capita consumption of electricity. It is, however, interesting to note that if in six years the present forecast should prove to be over-optimistic by, say, $500 \mathrm{MW}$ the additional capital changes would be noarly offset by savings in operating costs as a corresponding amount of the least efficient plant in operation could be taken out of service and scrapped.

Modern statistical techniques and computer studies are utilized on long- and medium-range forecasting. Distribution requirements having essentially a local and to some extent an individual character remain largely matters of judgment on the part of management.

Research is a primary factor in promoting the commercial development of the industry. For engineering research the supply industry has in the past relied largely on manufacturers and the co-operative work of the Electrical Research Association. It has, however, been realized that the industry requires to conduct a considerable research programme of its own and on this an amount of about $£ 6$ million is being spent per annum.

It is clear that insufficient national offort has boen directed to matters in which the characteristics of the consumer are of importance. Physiological, psychological and economic factors are involved. For example, the use of 'off peak' supplies for domestic and industrial purposes is increasing rapidly. Electric floor warming introduces a number of novel problems. Not least among the problems requiring investigation is that of the economies of such novel types of load. From the point of view of management, judgment and appraisal have to be applied to determining the sums to be allocated to research in its various aspects, and to the weight to be given to scientific and engineering opinion in the wider context of commercial and social implications. Management must, in fact, endervour to provide conditions in which engineers, physicists, mathematicians, economists and statisticians can co-operate fully and effectively in advancing the practice of electricity supply.

In the matter of tariffs, management has not only the overriding responsibility of ensuring an adequate total revenue but also a considerable power of influencing the development of demand in desirable directions. While there must be no undue preference for or discrimination against any consumer or class of consumer, there are opportunities for devising special tariffs which can be not only related to the special requirements but also can conduce by better distribution of demand to improvementis in the overall operation of the system.
Mr. Melling's third example was the most fundamental one-that of ensuring a supply of managers for one or two decades ahead. In the direct exercise of their professions, engineers, physicists, accountants or lawyers might give quite a good indication of thoir promise within a few years of graduation. The development of the potential manager and the demonstration of his qualities is a slower process. In Mr. Melling's opinion engineering provides, for management, as good a background as any other profession.

The supply industry, in developing its future managers, utilizes techniques common to most progressive industries. Potential managers attend courses in the industry's own residential training establishments, in universities and elsewhere. At the Electricity Council's training centre in Surrey are provided two types of course, one designed to promote general executive development through the medium of tackling unfamiliar problems by the syndicate method. The other studies individual subjects of importance to managers such as communication, organization and finance. The Generating Board and individual area boards organize similar training courses to meet their own needs. The facilities of the Administrative Staff College at Henley are also used.

Within the actual operating organization itself a system of regular appraisal is being used. This is designed to assess the potential of individuals and to formulate a scheme of training appropriate to individual needs. Following appraisal, selected members of staff may be sent on courses, given 'cross-postings' to new typos of work, or allocated to specific assignments. The aim is to provide exposure to some type of problem which has not been met before and which will exemplify human, as well as technical and economic, factors.

Many problems in any sphere of activity are necessarily those of the specialist, and management, in exercising judgment, is as often concerned to assess the qualities of the expert as the advice which he offers.

Academic qualifications, experience, and in some measure knowledge and intelligence are susceptible of direct assessment. The assessment of the qualities of the potential manager which relate to character and personality remains one of the most difficult of problems.

Mr. Melling completed his address by reviewing the role of the Institution of Electrical Engineers in fostering, through the Institution's educational requirements, the development of potential managers.

J. GREIG

\title{
THE DRAGON HIGH-TEMPERATURE REACTOR PROJECT
}

$\mathrm{T}$ HE third annual report of the Organization for European Co-operation and Development High Temperature Reactor Project (Dragon), covering the period from April 1, 1961 to March 31, 1962, has been issued by the European Nuclear Energy Agency*. The participants in the Project are the United Kingdom Atomic Energy Authority ; the Euratom Commission, consisting of the six countries, Belgium, France, Germany, Italy, Luxembourg and the Netherlands ; the Austrian Government ; the Danish Atomic Energy Commission ; the Norwegian Institut for Atomenergi ; $A B$ Atomenergi of Sweden; and the Swiss Government. The Project, which is based at Winfrith, Dorset, has as its principal aims the design, construction and operation of a $20-\mathrm{MW}$ high-temperature gas-cooled reactor, and a programme of research and development to explore the practical possibilities of this type of reactor and the technical problems resulting from

* Organization for Ficonomic Co-operation and Development: European Nuclear Energy Agency, O.F.C.D. Dragon High Temperature Reactor Project-Third Annual Report, 1961-6\%. Pp. 196. (Paris: Organization for Economic Co-operation and Development: European Nuclear Energy
Agency, 1962.) operation with temperatures close to $1,500^{\circ} \mathrm{C}$ in the core of the reactor. The Dragon reactor is not the only hightemperature reactor under construction. A similar reactor HGTR is being built for the Philadelphia Electric Company at Peach Bottom in the United States, and there has been continuous and close collaboration between the members of the United States Atomic Energy Commission and members of the Project concerning materials for the reactor cores, reactor physics and common design problems. The Dragon reactor is likely to be the first of the high-temperature reactors to be brought into operation. Fuel loading was expected to commence towards the end of 1962.

For 1961-62 expenditure on the Project is estimated at about $£ 4,000,000$ and for $1962-63$ about $£ 5,400,000$. The total cost of the original five-year programme ending in 1964 is now estimated at about $£ 15,000,000$, and a working party has been set up to examine the question of an extension of the five-year agreement. (It has recently been announced that the extension has been approved; Nature, 197,$129 ; 1963$. ) 
The annual report is divided into three main sections, dealing with research and development, reactor design and construction, and administration, respectively. In general, the technical predictions on which the project was originally based continue to be confirmed by experience. No significant changes in the basic concept have been necessary, though an important change in the safety principles has been decided on. The inner containment, which consists of a steel shell containing the reactor core, is to be filled with air instead of nitrogen, but the design is such that a return to nitrogen filling, if required, can still be made. The reactor pressure vessel has been successfully pressure and leak tested and delivered to the site. Its erection within the reactor building is proceeding. Steady progress has been made in the design of the fission product and helium purification systems, and a contract for the purification plant is expected to be placed shortly. Construction of the reactor building has advanced rapidly and the control building has been completed.

Theoretical studies during the year have been concentrated on 'burn-up calculations' and power and tempera. ture distributions. The distribution of radioactivity in the Dragon system has been estimated. The experimental reactor physics investigations carried out in the Zenith reactor continued until July, when the exclusive use of the Zenith reactor for the Dragon programme came to an end. Several measurements have been made and evaluated. Heat-transfer channel experiments simulating Dragon reactor conditions have been carried out at Risø, Denmark. Carbon transfer experiments have emphasized the importance of extremely pure graphite in the core. Barium has been found to have a strong catalytic influence on graphite corrosion while silica acts as an inhibitor. The graphite for the main reactor components other than the fuel elements has been delivered and is in the process of being machined. No firm decision has yet been taken as to whether a fission product emitting fuel or a fission product retaining fuel will be used for the first charge in the Dragon reactor, but development work has proceeded on both types and plans for manufacturing either type are in hand.

The report contains many other details of the core and graphite assemblies and control mechanisms together with numerous dimensional diagrams and photographs of the various components. Annexed to the report are charts showing the composition of the staff of the Project; the members of the Board of Management and the General Purposes Committee - the two international committees responsible for the direction of the Project; and a list of all major contracts placed up to March 31, 1962.

\section{S. Weintroub}

\section{RADIOACTIVITY IN HUMAN DIET}

$\mathrm{ACH}$ year, as a reminder of the hazards of the atomic C age, reports are issued by the Agricultural Research Council Radiobiological Laboratory of levels of radioactivity in human diet. The annual report, 1961-62*, includes a review of research designed to give better understanding of factors which influence the passage of radioactive material from fall-out into plants and animals, both by direct contamination of foliage and via the soil, finally appearing in the mixed diet of the human population. The results of this work range from a demonstration that deposition of strontium-90 in soils may be reliably predicted from figures for annual rainfall, to a final indictment of the Brazil-nut as a concentrator of radium and thorium from the soil on which it is grown; about 1,000 times as much of these isotopes are found in Brazil-nuts as in other nuts and fruits.

The report gives the mean ratio of strontium-90 to calcium in the total mixed diet as 6.2 picocuries per gram of calcium during 1961 as compared with 6.4 in 1960 and 9.0 in 1959 , the corresponding values for milk being 5.9 , 6.4 and 9.7. It is stressed, however, that the figures obtained so far do not as yet reflect the full effects of the resumption of nuclear testing in 1961, and the most recent

* Agricuitural Research Council: Radiobiological Laboratory. Annual Report, 1961-62. Pp. Xv+96. (London: H.M. Stationery Office, 1962.) measurements support the forecast that the situation in 1962 will not differ greatly from that in 1959 after the tests in 1958.

Reference is made in the report to a 'working level', which is defined as 130 picocuries of strontium-90 per gramme of calcium. Indefinite exposure at this level would induce in bone amounts of strontium-90 of approximately half the maximum permissible specified by the Medical Research Council. In fact, the recommendation of the Medical Research Council's second report, The Hazards to Man of Nuclear and Allied Radiations (Cmnd. 1225, December 1960), was that "if the concentration of strontium-90 in bone calculated as an average for any age group, including the groups of infants and young children, was found to be rising continuously and to have reached the level of one-half that recommended as the maximum permissible level for the population as a whole, a reassessment of the situation would be required". The derivation of a 'working level' in the diet, from a maximum permissible level in bone, is not explained in the report from the Agricultural Research Council, and the size of the margin of safety adopted is not given.

In view of this the implications of the term "working level' are difficult to assess and at best this seems a most unfortunate choice of words.

\section{PETROLEUM MULCH}

$I^{N}$ $\mathrm{N}$ arboriculture the word 'mulch' is usually associated with the compost of wet leaves, straw, etc., laid as a protection to the roots of newly planted or young trees, especially on inherently dry soils. Petroleum mulch, however, is a relatively recent product of research in the industry and although in some respects its behaviour and purpose are similar to traditional soil-dressings, its potentialities are probably more far-reaching and durable. In the autumn number of the Esso Magazine (1962), an informative and well-illustrated account of a petroleum mulch evolved by Esso Research is given. The efficacy of this product is now being tested and proved on a large number of sites in many different countries. Already results are most encouraging and augur well for yet another application of petroleum to the well-being of mankind.

Briefly, this type of mulch is in fact an inexpensive emulsion of petroleum resins, used as an agricultural spray for improving the growth and yield of crops of all kinds. Its function is four-fold: to warm the soil, to reduce evaporation, to protect against soil-erosion, and to retard the dispersal by rain-wash and other agents of 